\title{
Excessive Formation of Hydroxyl Radicals and Aldehydic Lipid Peroxidation Products in Cultured Skin Fibroblasts from Patients with Complex I Deficiency
}

\author{
Xiaoping Luo, ${ }^{\star}$ Sari Pitkänen, ${ }^{\ddagger}$ Sacha Kassovska-Bratinova, ${ }^{\S}$ Brian H. Robinson, ${ }^{\ddagger \S}$ and Denis C. Lehotay* \\ *Department of Pediatric Laboratory Medicine, Division of Clinical Biochemistry; ${ }^{\ddagger}$ Department of Biochemistry, University of Toronto; \\ and ${ }^{\S}$ Department of Genetics, The Research Institute, The Hospital for Sick Children, Toronto, Ontario, Canada M5G 1 X8
}

\begin{abstract}
Previous studies suggest oxygen free radicals' involvement in the etiology of cardiomyopathy with cataracts. To investigate the role of free radicals in the pathogenesis of the cardiomyopathy with cataracts and complex I deficiency, fibroblasts from patients were assessed for hydroxyl radical formation and aldehydic lipid peroxidation products with and without redox active agents that increase free radicals. The rate of hydroxyl radical formation in patient cells was increased over 2-10-fold under basal conditions, and up to 20-fold after menadione or doxorubicin treatment compared with normal cells. We also found an overproduction of aldehydes in patient cells both under basal conditions and after treatment. Both hydroxyl radicals and toxic aldehydes such as hexanal, 4-hydroxynon-2-enal, and malondialdehyde were elevated in cells from patients with three types of complex I deficiency. In contrast, acyloins, the less toxic conjugated products of pyruvate and saturated aldehydes, were lower in the patient cells.

Our data provide direct evidence for the first time that complex I deficiency is associated with excessive production of hydroxyl radicals and lipid peroxidation. The resultant damage may contribute to the early onset of cardiomyopathy and cataracts and death in early infancy in affected patients with this disease. (J. Clin. Invest. 1997. 99:28772882.) Key words: complex I deficiency • cardiomyopathy • cataracts $\bullet$ hydroxyl radicals $\bullet$ lipid peroxidation
\end{abstract}

\section{Introduction}

Five multi-enzyme complexes embedded in the inner mitochondrial membrane are resposible for the overall process of oxidative phosphorylation. Electrons are transferred from $\mathrm{NADH}$ or flavoprotein-linked substrates to $\mathrm{O}_{2}$ through a chain of enzyme complexes numbered I to IV. The function of these complexes is to couple electron transfer with proton translocation out of the mitochondrion. The electrochemical proton gradient created by electron transfer along the respiratory

\footnotetext{
Address correspondence to Denis C. Lehotay, Ph.D., Dept. of Pediatric Laboratory Medicine, Div. of Clinical Biochemistry, The Research Institute, The Hospital for Sick Children, 555 University Ave., Toronto, Ontario, Canada. Phone: 416-813-5911; FAX: 416-813-6257; E-mail: lehotay@sickkids.on.ca

Received for publication 24 January 1997 and accepted in revised form 27 March 1997.
}

J. Clin. Invest.

(C) The American Society for Clinical Investigation, Inc.

0021-9738/97/06/2877/06 \$2.00

Volume 99, Number 12, June 1997, 2877-2882 chain drives the production of ATP from ADP and phosphate by the enzyme complex ATP synthase (complex V) (1-5).

Patients with isolated NADH-ubiquinone oxidoreductase (complex I) deficiency most commonly present with fatal neonatal lactic acidosis or with Leigh's disease (5-8). More recently we showed that three more clinical phenotypes, cardiomyopathy and cataracts, hepatopathy and tubulopathy, and mild developmental delay can be associated with complex I deficiency (6).

The combination of congenital cataracts, hypertrophic cardiomyopathy, mitochondrial myopathy, and exercise-related lactic acidosis has been reported from the Netherlands by Sengers et al. (9). Cardiomyopathy with cataracts is now listed by the McKusick Register (Entry No. 212350) as an autosomal recessive condition with the onset of symptoms at birth, childhood, or early adulthood (10-14). Hypertrophic ventricular cardiomyopathy is also found in conjunction with lactic acidemia and encephalopathy in the fatal neonatal and Leigh's disease groups of complex I deficient patients $(4,6,8)$. In these patients a malfunction of the mitochondrial respiratory chain, which is reflected by an elevated lactate to pyruvate ratio $(\mathrm{L} / \mathrm{P}$ ratio $)^{1}$ in cultured skin fibroblasts, has been demonstrated (4, $8)$. Both cardiomyopathy and cataract formation have been linked to free radical damage in human and animal model systems $(14,15)$. Recent studies using Western blot analysis and enzymatic assay showed normal levels of copper zinc superoxide dismutase (CuZnSOD), but grossly elevated levels of the mitochondrial manganese superoxide dismutase (MnSOD) in cultured skin fibroblasts from patients with cardiomyopathy and cataracts (16). Southern blot analysis in heart muscle of the patient tested revealed multiple mitochondrial DNA deletions suggesting free radical damage (16). Further studies in a series of patient cell lines showed that induction of MnSOD and the appearance of excessive amounts of superoxide were common events in complex I deficiency (17). It was postulated that in some types of complex I deficiency, excessive production of superoxide from the compromised electron transport chain combined with induction of MnSOD would lead to damage from increased hydroxyl radical formation (17).

While the above evidence pointed indirectly to the involvement of oxygen free radicals in the etiology of cardiomyopathy with cataracts, a more direct proof was needed. To investigate in greater depth the involvement of free radical injury in the pathogenesis of the cardiomyopathy with cataracts and complex I deficiency, skin fibroblasts from a group of patients were assessed for hydroxyl radical production and aldehydic lipid peroxidation products with and without redox active agents

\footnotetext{
1. Abbreviations used in this paper: DHBA, dihydroxybenzoic acid; $\mathrm{L} / \mathrm{P}$ ratio, lactate/pyruvate ratio; $\mathrm{MnSOD}$, mitochondrial manganese superoxide dismutase; $\mathrm{PDH}$, pyruvate dehydrogenase; SIR, selected ion recording.
} 
known to cause cell injury by free radical-mediated mechanisms $(18,19)$.

\section{Methods}

Patients. Patient 5221 was a female infant born at 42 wk by elective cesarean section. The birth weight was $2.59 \mathrm{~kg}$. An electrocardiogram, performed due to early cardiovascular instability, showed right ventricular hypertrophy, and an echocardiogram revealed pericardial effusion, hypertrophic cardiomyopathy, and poor ventricular function. On ophthalmic consultation bilateral dense white cataracts were observed. She died at $12 \mathrm{~d}$ of age of cardiac failure. The patient was from a Pakistani-Canadian family and had two healthy siblings. Patients 5624 and 6275 were from two different families who had complex I deficiency. They both presented with hepatopathy and tubulopathy but without cardiomyopathy and cataracts. Patient 5624 died from neurodegeneration (Leigh's disease), whereas patient 6275 is still alive without neurodegeneration (17).

Skin fibroblasts culture. Human skin fibroblasts (cell lines: control 4212; patient 5221; patient 5624; patient 6275) were grown from explants of forearm skin biopsies taken with informed parental consent and cultured in Eagle's minimal essential medium supplemented with $10 \%$ (vol/vol) FCS and $10.5 \mathrm{mM}$ glucose. Biochemical measurements of hydroxyl radicals, aldehydes, and acyloins were performed in several normal fibroblast cell lines as well as in the cells of affected patients. The data shown in Results for control is from 4212, a representative control cell line.

Determination of $L / P$ ratios and respiratory chain enzyme activities. $\mathrm{L} / \mathrm{P}$ ratios were determined as described previously by measuring the levels of lactate and pyruvate in the incubation medium of cultured fibroblasts after $1 \mathrm{~h}$ incubation in Krebs phosphate buffer $(\mathrm{pH}$ 7.4) containing $1 \mathrm{mM}$ glucose (20). Rotenone-sensitive NADH-cytochrome $c$ reductase activity (complex I and III) was measured in sonicated mitochondria, isolated from cultured skin fibroblasts following the method of Moreadith et al. (21). All required protein concentrations were assayed by the method of Lowry et al. (22).

Superoxide and MnSOD assay. The method used for the assay of superoxide activity was as described by Pitkänen and Robinson (17). The MnSOD ELISA kit (Bender MedSystems, Vienna, Austria), an enzyme-linked immunosorbent assay was used to quantify MnSOD levels in mitochondrial samples made from patients' cultured fibroblasts (17).

Hydroxyl radicals measurement. Hydroxyl radicals formation was measured by an aromatic hydroxylation assay recently developed in our laboratory using salicylate as a probe (23). Skin fibroblasts from patients (cell lines 5221, 5624, and 6275) and control (cell line 4212) were incubated with $2 \mu \mathrm{M}$ salicylate and $25 \mu \mathrm{M}$ menadione or doxorubicin for $2 \mathrm{~h}$. The cells were scraped from the dish. $100 \mu \mathrm{l}$ of cells were collected and sonicated in $1 \mathrm{ml}$ water containing EDTA $(400 \mu \mathrm{mol})$, BHT and desferal $(20 \mu \mathrm{mol}$ for both $)$ on ice. $20 \mu \mathrm{l}$ of $5 \mu \mathrm{M}(0.1 \mathrm{nmol})$ benzoic acid (ring- $\mathrm{D}_{5}, 98 \%$; Cambridge Isotope Laboratories Inc., Andover, MA) was added to the sample as an internal standard. $100 \mu \mathrm{l}$ BSTFA in 1\% TMCS was added to the sample and incubated for 10 $\min$ at $60^{\circ} \mathrm{C}$. The trimethylsilyl (TMS) derivatives were analyzed using a high-sensitivity research grade quadrupole mass spectrometer (VG-Trio 2A) interfaced to a gas chromatograph (5890 series; Hewlett Packard, Palo Alto, CA) equipped with a 30 m, 0.32 m DB-5 capillary column. Quantitation was achieved by selected-ion recording (SIR). Specific ions for benzoic acid (ring- $\mathrm{D}_{5}$ ), catechol, 2,3-dihydroxybenzoic acid (2,3-DHBA), and 2,5-dihydroxybenzoic acid (2,5DHBA) were $180,254,355$, and 355 , respectively. The compounds were well separated by the GC with retention times of $7.50,8.40$, 15.12 , and $15.54 \mathrm{~min}$. The detection limit was between $100 \mathrm{fmol}$ and 1 pmol per $1 \mu$ injection.

Measurement of aldehydes and acyloins. 20 aldehydes from $\mathrm{C}_{2}-$ $\mathrm{C}_{12}$ including some unsaturated or hydroxyl aldehydes were measured in skin fibroblasts using a GC-MS method (24). Five acyloins (3-hydroxy-heptan-2-one, 3-hydroxy-octan-2-one, 3-hydroxy-nonan2-one, 3-hydroxy-decan-2-one, and 3-hydroxy-dodecan-2-one) were also measured at the same time. The specific ions of acyloins for SIR were $126,140,244,258$, and 287, respectively. The acyloin concentrations were estimated according to their relevant aldehydes since their standards were not commercially available. For a dose-response experiment, cell line 5221 and control cell line 4212 were treated with menadione $(10,25,50 \mu \mathrm{M})$ and doxorubicin $(5,25,50 \mu \mathrm{M})$ for $2 \mathrm{~h}$. Measurements were also made using $25 \mu \mathrm{M}$ of menadione or doxorubicin at $0.5,1,2,3$, and $6 \mathrm{~h}$. To compare aldehyde levels in cells from patients with different clinical patterns, cell line 5624 and cell line 6275 were also treated with $25 \mu \mathrm{M}$ of menadione for $2 \mathrm{~h}$. Cell collection and sonication procedures were the same as for hydroxyl radical measurement.

\section{Results}

$L / P$ ratios and enzyme activities. $\mathrm{L} / \mathrm{P}$ ratios and enzyme activities of cultured skin fibroblasts are shown in Table I. The L/P ratios were 4-5 times higher than control in all 3 patients. Rotenone-sensitive NADH-cytochrome $c$ reductase (complex I and III) activities in mitochondria were decreased to 54, 19, and $29 \%$ of control activity for patient 5221, 5624, and 6275 , respectively. Superoxide production was significantly reduced in patient 5221 but only slightly decreased in patient 5624 and 6275. MnSOD levels were remarkably increased to 370,258 , and $249 \%$ of control for patient 5221,5624 , and 6275 , respectively.

Detection of hydroxyl radicals by aromatic hydroxylation. Fig. 1 shows concentration of products of hydroxyl radical attack on salicylate in fibroblasts ( $A$, catechol; $B, 2,3$-DHBA; $C$, 2,5-DHBA). Cell line 5221 had the highest level for all three compounds both under basal conditions, and after menadione or doxorubicin treatment. These levels were 5-10-fold higher than in normal cells under basal conditions and increased up to 10-20-fold after treatment. Concentration of hydroxylation products in cell lines 5624 and 6275 were significantly higher

Table I. L/P Ratios and Enzyme Activities of Cultured Skin Fibroblasts

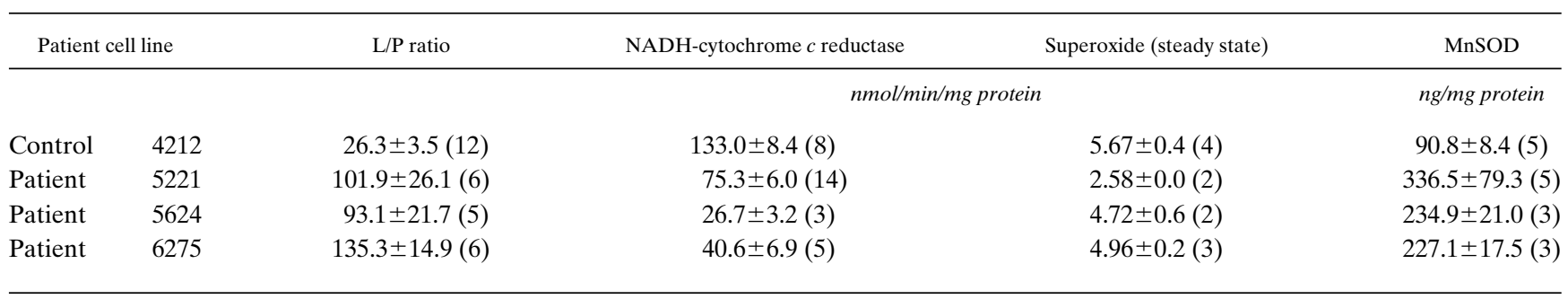

The results are expressed as mean \pm SE with the number of determinations given in parentheses. For each determination of respiratory chain activity a fresh batch of mitochondria was prepared. 


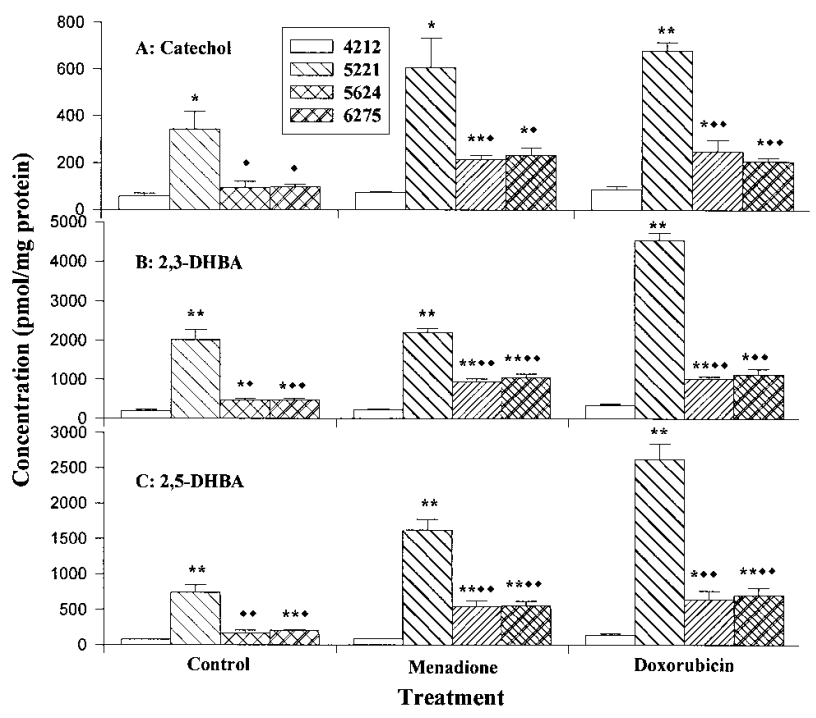

Figure 1. Products of hydroxyl radical attack on salicylate in fibroblasts. Cells were treated with $2 \mu \mathrm{M}$ salicylate and $25 \mu \mathrm{M}$ menadione or doxorubicin for $2 \mathrm{~h}$. Data presented as mean \pm SD. (cell line 4212 , control; cell line 5221, complex I deficiency patient 5221 with cardiomyopathy and cataracts; cell lines 5624 and 6275, complex I deficiency patient 5624 and 6275 with hepatopathy and tubulopathy. $* P<0.05,{ }^{* *} P<0.01$ compared to control cell; ${ }^{*} P<0.05$, $\bullet P<0.01$ compared to cell line 5221.)

than in control in most cases, but were remarkably lower than in cell line 5221.

Aldehydic lipid peroxidation products. Fig. 2 shows the effect of increasing dose of menadione or doxorubicin treatment on aldehyde and acyloin production in skin fibroblasts. The total aldehyde concentration was significantly higher in cell line
5221 than in control both under basal conditions, and after menadione or doxorubicin treatment in a dose-related manner. The acyloin production however revealed a different pattern in which the control cells produced more acyloins and exhibited a more significant dose-related increase after menadione or doxorubicin treatment.

Fig. 3 shows the time course of aldehyde and acyloin production during $25 \mu \mathrm{M}$ menadione or doxorubicin treatment. The aldehyde levels in cell line 5221 increased significantly at a very early stage and continued to increase until the cells died. On the other hand, there were only slight increases in control cell lines and the cells survived the 6-h incubation. In contrast, acyloin levels in control cells increased after menadione or doxorubicin treatment and were higher than patient cells at all time points.

Aldehyde and acyloin production in skin fibroblasts from patients with different clinical patterns of complex I deficiency after $25 \mu \mathrm{M}$ menadione treatment are shown in Fig. 4. Aldehyde levels in cell line 5221 were the highest both under basal conditions, and $2 \mathrm{~h}$ after treatment, while the levels in cell lines 5624 and 6275 were only slightly higher than control despite the fact that hydroxyl radical production rates were higher than control in these cells. The production of acyloins in cell line 5221 was the lowest compared with control cells and other deficient cells. Control cells had the greatest increase in acyloin production after menadione treatment.

Fig. 5 shows toxic aldehyde levels for hexanal, 4-hydroxynon-2-enal (HNE), and malondialdehyde (MDA) in different cells. Cell line 5221 had the highest level for all three toxic aldehydes after $25 \mu \mathrm{M}$ menadione treatment and showed a 1.52 -fold stimulation with menadione in their production as also shown by the other cell lines. The most abundant aldehydes were (in order of abundance) propanal, butanal, furfural, nonanal, MDA, octanal, decanal, heptanal, hexanal, pentanal, dodecanal, trans-2-nonenal, HNE. The concentrations of the individual aldehydes in control cells varied from 50 to 0.5

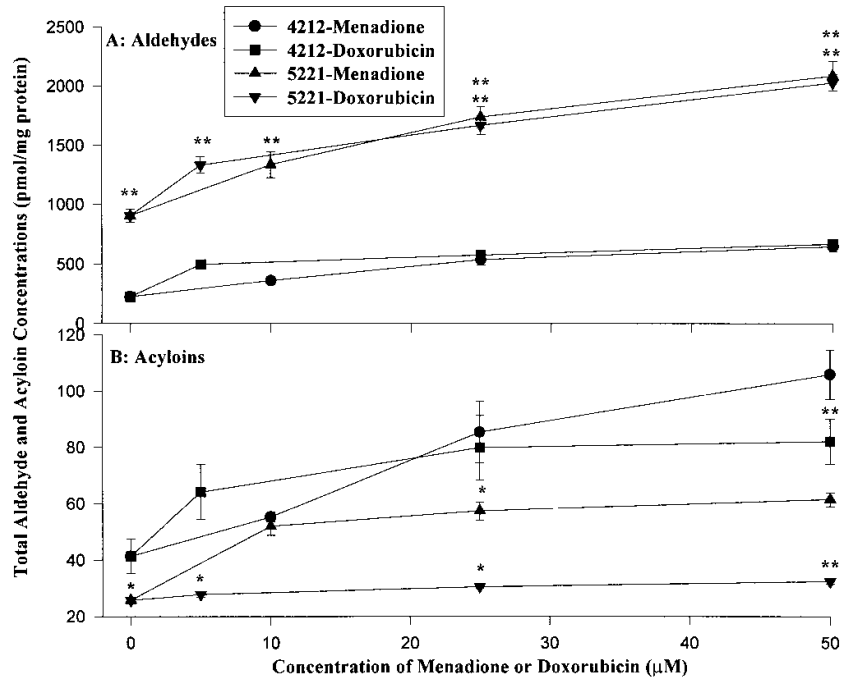

Figure 2. Aldehyde and acyloin production following increasing doses of menadione or doxorubicin. Cells were treated with menadione $(10,25$, and $50 \mu \mathrm{M})$ or doxorubicin $(5,25$, and $50 \mu \mathrm{M})$ for $2 \mathrm{~h}$. Data presented as mean \pm SD. (Cell line 4212 , control; cell line 5221, complex I deficiency patient 5221 with cardiomyopathy and cataracts. $* P<0.05, * * P<0.01$ compared to control cell.)

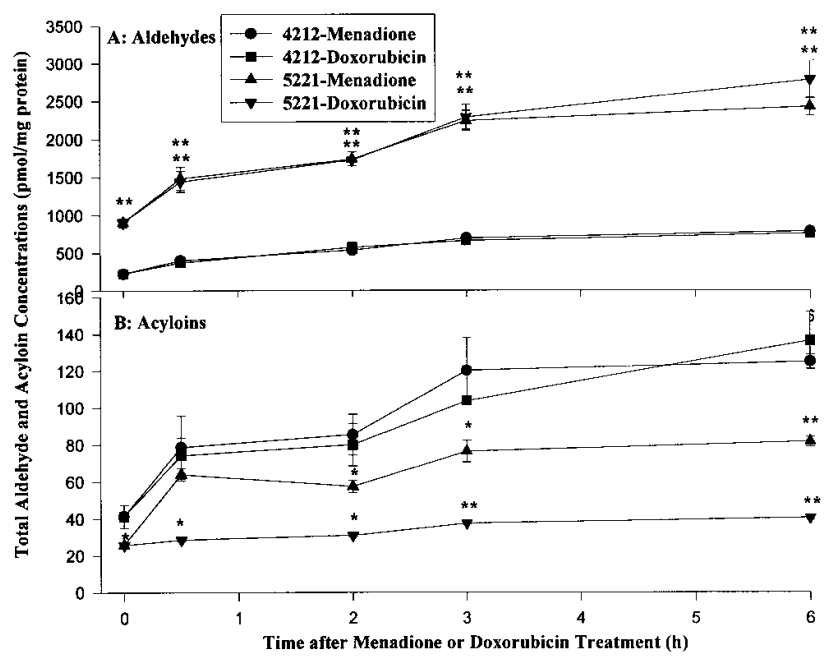

Figure 3. Time course of aldehyde and acyloin production following menadione or doxorubicin treatment. Cells were treated with $25 \mu \mathrm{M}$ menadione or doxorubicin for $0.5,1,2,3$, and $6 \mathrm{~h}$. Data presented as mean \pm SD. (Cell line 4212, control; cell line 5221, complex I deficiency patient 5221 with cardiomyopathy and cataracts. ${ }^{*} P<0.05$, $* * P<0.01$ compared to control cell.) 


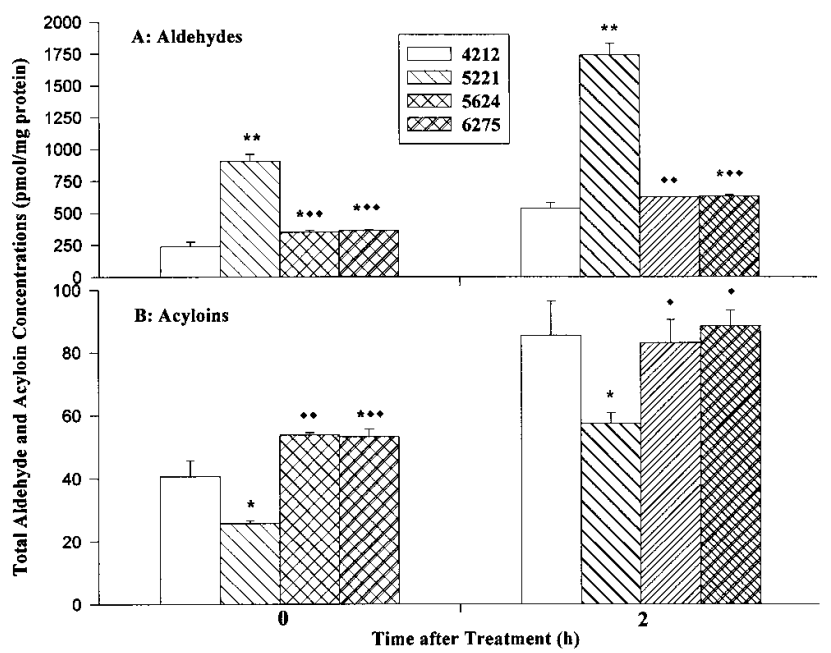

Figure 4. Aldehyde and acyloin production in different cells after menadione $(25 \mu \mathrm{M})$ treatment. Cells were treated with $25 \mu \mathrm{M}$ menadione for $2 \mathrm{~h}$. Data presented as mean \pm SD. (Cell line 4212, control; cell line 5221, complex I deficiency patient 5221 with cardiomyopathy and cataracts; cell lines 5624 and 6275, complex I deficiency patient 5624 and 6275 with hepatopathy and tubulopathy. $* P<0.05, * * P<$ 0.01 compared to control cell; $\bullet P<0.05,{ }^{\bullet} P<0.01$ compared to cell line 5221.)

$\mathrm{pmol} / \mathrm{mg}$ protein from the most to the least abundant of the 20 measured aldehydes.

\section{Discussion}

Oxidative stress in cells and tissues is thought to be a direct result of increased generation of superoxide radicals. When excess superoxide is reacted upon by MnSOD, large amounts of

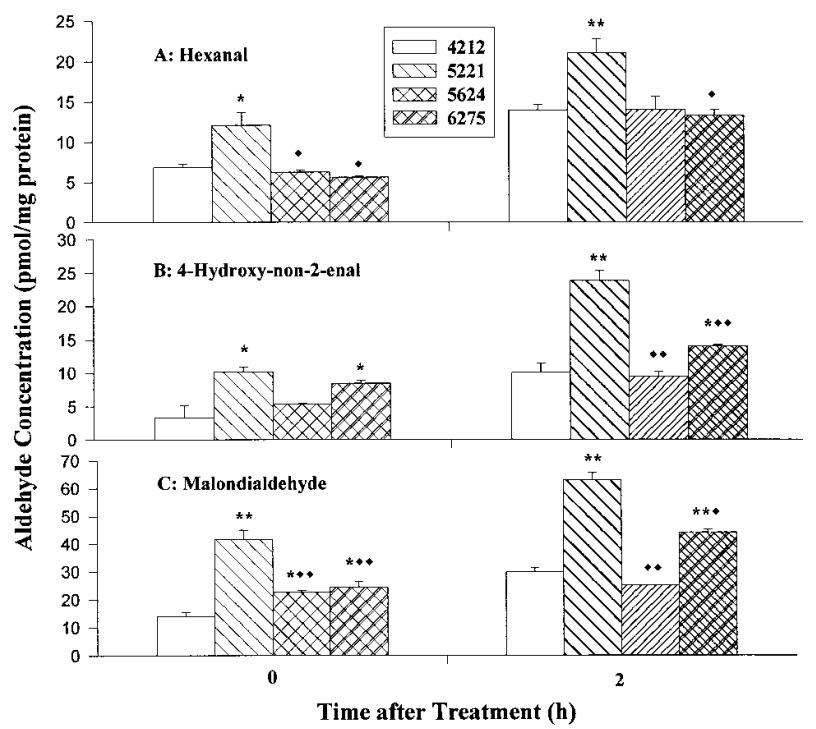

Figure 5. Toxic aldehydes in different cells after menadione $(25 \mu \mathrm{M})$ treatment. Cells were treated with $25 \mu \mathrm{M}$ menadione for $2 \mathrm{~h}$. Data presented as mean \pm SD. (Cell line 4212, control; cell line 5221, complex I deficiency patient 5221 with cardiomyopathy and cataracts; cell lines 5624 and 6275, complex I deficiency patient 5624 and 6275 with hepatopathy and tubulopathy. ${ }^{*} P<0.05, * * P<0.01$ compared to control cell; $\bullet^{\bullet} P<0.05,{ }^{\bullet} P<0.01$ compared to cell line 5221.) intramitochondrial hydrogen peroxide are produced. Neither superoxide nor hydrogen peroxide is very toxic. However, in the presence of metal ion catalysts these species are converted to hydroxyl radicals through a Fenton reaction or HaberWeiss reaction (25-27). Interaction between superoxide and nitric oxide can also form hydroxyl radicals or peroxynitrile (28). The highly reactive hydroxyl radicals readily react with a variety of molecules and cause membrane lipid peroxidation, protein aggregation, and DNA hydroxylation (29).

Hydroxyl radicals react with biological molecules in a diffusion-controlled fashion. Since their half-life in cells has been estimated to be $10^{-9} \mathrm{~s}$, their measurement is very difficult (30). The two trapping methods with the greatest potential for specifically identifying hydroxyl radicals are electron spin resonance-spin trapping (31) and aromatic hydroxylation (32).

In the present study using aromatic hydroxylation, salicylate was used as a probe, which can be attacked by hydroxyl radicals at $\mathrm{pH} 7.4$ to give three products: 2,3-DHBA, 2,5DHBA, and catechol. As reported in the literature, 2,5-DHBA can also be generated from salicylate by enzymes such as cytochrome P-450 in vivo, but 2,3-DHBA is thought to be produced by only hydroxyl radical attack on salicylate $(33,34)$. Our results demonstrated that the hydroxylation products increased over 2- to 10-fold under basal conditions, and up to 20fold after menadione or doxorubicin treatment in skin fibroblasts from patients with varying types of complex I deficiency. These data provide direct evidence that excessive hydroxyl radicals are produced in this syndrome under both normal and oxidative stress conditions.

Free radicals are generally short lived and inflict damage only in the local environment where they are produced. Recent studies indicate that free radical-initiated lipid peroxidation also results in the production of a great variety of stable, diffusible, saturated, and unsaturated aldehydes. These cytotoxic aldehydes are relatively stable and biologically active. They can attack targets far from the site of the original free radical-initiated event and may act as "secondary cytotoxic messengers" of free radicals. They are now considered as one of the few measurable parameters indicative of lipid peroxidation in vivo (29, 35-37). Hexanal, HNE, and MDA are among the most toxic aldehydes and have metabolic, genotoxic, and mutagenic effects, as well as inhibitory effects on cell proliferation (36-40). Our data clearly revealed a remarkable overproduction of aldehydes in skin fibroblasts from a patient with cardiomyopathy and cataracts both under basal conditions and after menadione or doxorubicin treatment. The increment was dose dependent and correlated with the course of cell death. These data strongly suggest that extensive lipid peroxidation occurred during the cell damage process.

Studies have shown that pyruvate dehydrogenase (PDH) catalyses a conjugation reaction between pyruvate and saturated aldehydes to produce acyloins (3-hydroxyalkan-2-one), which can then be reduced endogenously to the corresponding 2,3-alkanedials. Since acyloins and 2,3-alkanedials are stable and less toxic products, these reactions may serve as an alternative and ubiquitous detoxification mechanism for saturated aldehydes produced by lipid peroxidation (41-42). In our experiments, the acyloin levels in skin fibroblasts of the cardiomyopathy with cataracts patient were much lower than the control value despite increased production of toxic aldehydes. This suggests that PDH or PDH-acyloin synthase was impaired or inhibited in patient cells, which may have contrib- 
uted to their vulnerability to oxidative stress and increased measurable toxic aldehyde levels. Our data suggest that the changed redox state increased NADH/NAD ratio by a factor of four, accompanied probably by increased acetyl CoA/ $\mathrm{CoASH}$ ratios due to impaired acetyl CoA oxidation in the Krebs cycle. These factors would conspire together to both feedback inhibit the PDH complex and to promote inactivation of the PDH complex by PDH kinase (43).

Increased generation of hydroxyl radicals is known to induce cataract formation, cardiomyopathy, and premature aging in certain rat strains (15). Mitochondria are active in continuous generation of semiquinone radicals, reactive oxygen species and in lipid peroxidation (44). It is known that the mitochondrial respiratory chain, especially complex $\mathrm{I}$, is the main source of superoxide in nonphagocytic cells, probably via autoxidation of ubiquinone generated during electron transport $(17,45-47)$. Impairment of complex I activity by blocking electron transport with inhibitors causes increased production of superoxide $(17,48)$.

The mitochondrial enzyme, MnSOD, converts superoxide to hydrogen peroxide, and these two species in turn can generate the highly potent oxidants such as the hydroxyl radicals and singlet oxygen through metal-chelate-complex-catalyzed reactions (49-51). Our studies with skin fibroblasts showed that there is considerable variation between patients in the state of induction of MnSOD activity, which is a function not of the degree of impairment of the electron flow in complex I but instead is a function of the change in cellular redox state $(16,17)$. Thus the excessive formation of hydroxyl radicals and aldehydic lipid peroxidation products demonstrated here again seems to be greatest in the cell line with the highest MnSOD activity. Even though the other two complex I deficient patients in this study have a more severe defect in electron transport, they have only a modest increase in production of hydroxyl radicals (X2) and milder symptoms. This emphasizes the fact that pathogenicity may be a combined function of oxidative phosphorylation impairment and excess hydroxyl radical production. Since the latter parameter we have shown to be a function of the induction of MnSOD, this would explain our findings that hydroxyl radical production is associated with more severe disease (17). In the case of the syndrome of cardiomyopathy with cataracts and complex I deficiency, where breakage of mtDNA in the heart was observed, this may have been due to excessive hydroxyl radical production, while the hydroxylation and disruption of lens proteins in the eye might be responsible for cataracts formation. An impairment of detoxification mechanism such as PDH or PDH-acyloinsynthase could also play a role in the pathogenesis. Further studies are needed to elucidate the site of superoxide production in terms of the participation of the different subunits of complex I in normal and deficient cell lines, and to elucidate the mechanism of MnSOD induction.

\section{Acknowledgments}

This research was supported by the Canadian National Centers of Excellence Program, the Heart and Stroke Foundation of Canada, and the Emil Aaltonen Foundation of Finland.

\section{References}

1. Hammans, S.R., and A.E. Harding. 1991. Mitochondrial disease and mitochondrial DNA. Br. J. Hosp. Med. 46:20-26.
2. Weiss, H., T. Friedrich, G. Hofhaus, and D. Preis. 1991. The respiratorychain NADH dehydrogenase (complex I) of mitochondria. Eur. J. Biochem. 197:563-576.

3. Hatefi, Y. 1985. The mitochondrial electron transport and oxidative phosphorylation system. Annu. Rev. Biochem. 54:1015-1069.

4. Robinson, B.H. 1993. Lacticacidemia. Biochim. Biophys. Acta. 1182:231-244.

5. Wallace, D.C. 1992. Diseases of the mitochondrial DNA. Annu. Rev. Biochem. 61:1175-1212.

6. Pitkänen, S., A. Feigenbaum, R. Laframboise, and B.H. Robinson. 1996. NADH-coenzyme Q reductase (complex I) deficiency: heterogeneity in phenotype and biochemical findings. J. Inher. Metab. Dis. 19:675-686.

7. Fujii, T., M. Ito, T. Okuno, K. Mutoh, R. Nishikomori, and H. Mikawa 1990. Complex I (reduced nicotinamide-adenine dinucleotide-coenzyme Q reductase) deficiency in two patients with probable Leigh syndrome. J. Pediatr. 116:84-87.

8. Robinson, B.H., D.M. Glerum, W. Chow, R. Petrova-Benedict, R. Lightowlers, and R. Capaldi. 1990. The use of skin fibroblast cultures in the detection of respiratory chain defects in patients with lacticacidemia. Pediatr. Res. 28: 549-555.

9. Sengers, R.C.A., B.G.A. ter Haar, J.M.F. Trijbels, J.L. Willems, O. Daniels, and A.M. Stadhouders. 1975. Congenital cataract and mitochondrial myopathy of skeletal and heart muscle associated with lactic acidosis after exercise. J. Pediatr. 86:873-880.

10. McKusick, V.A. 1992. Mendelian inheritance in man. In Catalogs of Autosomal Dominant, Autosomal Recessive, and X-linked Phenotypes. Tenth edition, Johns Hopkins University Press, Baltimore, MD.

11. Sengers, R.C.A., A.M. Stadhouders, E. van Lakwijk-Vondrovicova, K Kubat, and W. Ruitenbeek. 1985. Hypertrophic cardiomyopathy associated with a mitochondrial myopathy of voluntary muscles and congenital cataracts. Br. Heart. J. 54:543-547.

12. Cruysberg, J.R.M., R.C.A. Sengers, A. Pinckers, K. Kubat, and U.J.G.M. van Haelst. 1986. Features of a syndrome with congenital cataract and hypertrophic cardiomyopathy. Am. J. Ophthal. 102:740-749.

13. Valsson, J., T. Laxdal, A. Jonsson, K. Kristjansson, and H. Helgason 1988. Congenital cardiomyopathy and cataracts with lactic acidosis. Am. J. Cardiol. 61:193-194.

14. Bhuyan, D.K., and K.C. Bhuyan. 1994. Assessment of oxidative stress to eye in animal model for cataract. Methods Enzymol. 233:630-639.

15. Salganik, R.I., N.A. Solovyova, S.I. Dikalov, O.N. Grishaeva, L.A. Semenova, and A.V. Popovsky. 1994. Inherited enhancement of hydroxyl radical generation and lipid peroxidation in the $S$ strain rats results in DNA rearrangements, degeneration diseases, and premature aging. Biochem. Biophys. Res. Commun. 199:726-733.

16. Pitkänen, S., F. Merante, D.R. McLeod, D. Applegarth, T. Tong, and B.H Robinson. 1996. Familial cardiomyopathy with cataracts and lactic acidosis: a defect in complex I (NADH-dehydrogenase) of the mitochondria respiratory chain. Pediatr. Res. 39:513-521.

17. Pitkänen, S., and B.H. Robinson. 1996. Mitochondrial complex I deficiency leads to increased production of superoxide radicals and induction of superoxide dismutase. J. Clin. Invest. 98:345-351.

18. Frei, B., K.H. Winterhalter, and C. Richter. 1986. Menadione (2-methylnaphtoquinone)-dependent enzymatic redox cycling and calcium release by mitochondria. Biochemistry. 25:4438-4443.

19. Lown, W. 1993. Anthracycline and anthraquinone anticancer agents: current status and recent development. Pharmacol. Ther. 60:185-214.

20. Robinson, B.H, N. Mackay, P. Goodyer, and G. Lancaster. 1985. Defective intramitochondrial NADH oxidation in skin fibroblasts from an infant with fatal neonatal lacticacidemia. Am. J. Hum. Genet. 37:938-946.

21. Moreadith, R.W., M.L. Batshaw, T. Ohnishi, D. Kerr, B. Knowx, D. Jackson, R. Hruba, J. Olson, B. Reynafarje, and A.L. Lehninger. 1984. Deficiency of the iron-sulfur clusters of mitochondrial reduced nicotinamide-adenine dinucleotide-ubiquinone oxidoreductase (complex I) in an infant with congenital lactic acidosis. J. Clin. Invest. 74:685-697.

22. Lowry, O.H., N.J. Rosebrough, A.L. Farr, and R.J. Randall. 1951. Protein measurement with the Folin phenol reagent. J. Biol. Chem. 193:265-275.

23. Luo, X.P., and D.C. Lehotay. 1997. Determination of hydroxyl radicals using salicylate as a trapping agent by gas chromatography-mass spectrometry. Clin. Biochem. 30:41-46.

24. Luo, X.P., M. Yazdanpanah, N. Bhooi, and D.C. Lehotay. 1995. Determination of aldehydes and other lipid peroxidation products in biological samples by gas chromatography-mass spectrometry. Anal. Biochem. 228:294-298.

25. Shull, S., N.H. Heintz, M. Periasamy, M. Manohar, Y.M.W. Janssen, J.P. Marsh, and B.T. Mossman. 1991. Differential regulation of antioxidant enzymes in response to oxidants. J. Biol. Chem. 266:24398-24403.

26. Hockenbery, D.M., Z.N. Oltvai, X.-M. Yin, C.L. Milliman, and S.J. Korsmeyer. 1993. Bcl-2 functions in an antioxidant pathway to prevent apoptosis. Cell. 75:241-251.

27. O’Donnell, V., and M.J. Burkitt. 1994. Mitochondrial metabolism of a hydroperoxide to free radicals in human endothelial cells: an electron spin resonance spin-trapping investigation. Biochem. J. 304:707-713.

28. Beckman, J.S, T.W. Beckman, J. Chen, P.A. Marshall, and B.A. Freeman. 1990. Apparent hydroxyl radical production by peroxynitrite: implications 
for endothelial injury from nitric oxide and superoxide. Proc. Natl. Acad. Sci. USA. 87:1620-1624.

29. Cheeseman, K.H., and T.F. Slater. 1993. An introduction to free radical biochemistry. Br. Med. Bull. 49:481-493.

30. Kaur, H., and B. Halliwell. 1994. Detection of hydroxyl radicals by aromatic hydroxylation. Methods Enzymol. 233:67-82.

31. Yamazaki, I., and L.H. Piette. 1990. ESR spin-trapping studies on the reaction of $\mathrm{Fe}^{2+}$ ions with $\mathrm{H}_{2} \mathrm{O}_{2}$-reactive species in oxygen toxicity in biology. $J$. Biol. Chem. 265:13589-13594.

32. Halliwell, B. 1978. Superoxide-dependent formation of hydroxyl radicals in the presence of iron chelates: is it a mechanism for hydroxyl radical production in biochemical systems? FEBS Lett. 92:321-326.

33. Richmond, R., B. Halliwell, J. Chauhan, and A. Darbre. 1981. Supperoxide-dependent formation of hydroxyl radicals: detection of hydroxyl radicals by the hydroxylation of aromatic compounds. Anal. Biochem. 118:328-335.

34. Ingelman-Sundberg, M., H. Kaur, Y. Terelius, J.O. Persson, and B. Halliwell. 1991. Hydroxylation of salicylate by microsomal fractions and cytochrome P-450. Lack of production of 2,3-dihydroxybenzoate unless hydroxyl radical formation is permitted. Biochem. J. 276:753-757.

35. Esterbauer, H., and H. Zollner. 1989. Methods for determination of aldehydic lipid peroxidation products. Free Radical Biol. Med. 7:197-203.

36. Esterbauer, H., R.J. Schaur, and H. Zollner. 1991. Chemistry and biochemistry of 4-hydroxynonenal, malondialdehyde and related aldehydes. Free Radical Biol. Med. 11:81-128.

37. Loidl-Stahlhofen, A., and G. Spiteller. 1994. alpha-Hydroxyaldehydes, products of lipid peroxidation. Biochim. Biophys. Acta. 1211:156-160.

38. Witz, G. 1989. Biological interactions of $\alpha, \beta$-unsaturated aldehydes. Free Radical Biol. Med. 7:333-349.

39. Toyokuni, S., K. Uchida, K. Okamoto, Y. Hattori-Nakakuki, H. Hiai, and E.R. Stadtman. 1994. Formation of 4-hydroxy-2-nonenal-modified proteins in the renal proximal tubules of rats treated with a renal carcinogen, ferric nitrolotriacetate. Proc. Natl. Acad. Sci. USA. 91:2616-2620.

40. Alary, J., F. Bravais, J.-P. Cravedi, L. Debrauwer, D. Rao, and G. Bo- ries. 1995. Mercapturic acid conjugates as urinary end metabolites of the lipid peroxidation product 4-hydroxy-2-nonenal in the rat. Chem. Res. Toxicol. 8:34-39.

41. Montgomery, J.A., C. Des Rosiers, and H. Brunengraber. 1992. Biosynthesis and characterization of 3-hydroxyalkan-2-ones and 2,3-alkanediols: potential products of aldehyde metabolism. Biol. Mass. Spectr. 21:242-248.

42. Montgomery, J.A., M. Jetté, S. Huot, and C. Des Rosiers. 1993. Acyloin production from aldehydes in the perfused rat heart: the potential role of pyruvate dehydrogenase. Biochem. J. 294:727-733.

43. Reed, L.J. 1981. Regulation of mammalian pyruvate dehydrogenase complex by a phosphorylation-dephosphorylation cycle. Curr. Topics Cell Regul. 18:95-106.

44. Richter, C. 1992. Reactive oxygen and DNA damage in mitochondria Mutat. Res. 275:249-255.

45. Hennet, T., C. Richter, and E. Peterhans. 1993. Tumor necrosis factoralpha induces superoxide anion generation in mitochondria of L929 cells. Biochem. J. 289:587-592.

46. Turrens, J.F., and A. Boveris. 1980. Generation of superoxide anion by the NADH dehydrogenase of bovine heart mitochondria. Biochem. J. 191:421-427.

47. Turrens, J.F., B.A. Freeman, J.G. Levitt, and J.D. Crapo. 1982. The effect of hyperoxia on superoxide production by lung submitochondrial particles. Arch. Biochem. Biophys. 217:401-410.

48. Flint, D.H., J.F. Tuminello, and M.H. Emptage. 1993. The inactivation of Fe-S cluster containing hydro-lyases by superoxide. J. Biol. Chem. 268 22369-22376.

49. Sies, H. 1991. Oxidative stress: from basic research to clinical application. Am. J. Med. 91:31s-38s.

50. Fridovich, I. 1995. Superoxide radical and superoxide dismutases. Annu. Rev. Biochem. 64:97-112.

51. Sanders, S.P., J.L. Zweier, P. Kuppusamy, S.J. Harrison, D.P. Bassett, E.W. Gabrielson, and J.T. Sylvester. 1993. Hyperoxic sheep pulmonary microvascular endothelial cells generate free radicals via mitochondrial electron transport. J. Clin. Invest. 91:46-52. 